\title{
Infections in continuous ambulatory peritoneal dialysis
}

\author{
R. C. SPENCER
}

Department of Bacteriology, Royal Hallamshire Hospital, Glossop Road, Sheffield S10 2JF

\section{Introduction}

The concept that the peritoneal membrane could be used as a means of removing solutes from the blood originated in the 1890s (Starling and Tubby, 1894) and peritoneal dialysis was first used for the treatment of renal failure in man by Ganter (1923). In the past, access to the peritoneal cavity was through several techniques and devices which needed frequent changing. 1968 saw the introduction of the Tenckhoff ind welling peritoneal catheter which had an average lifespan of approximately 20 months (Tenckhoff and Schechter, 1968). This was the first permanent, relatively safe, silastic peritoneal access device. In 1976 a new technique was described-Continuous Ambulatory Peritoneal Dialysis (CAPD) - which allowed fluid to remain in the peritoneal cavity for 4-8h instead of an exchange of dialysate every hour (Popovich et al., 1976). Although the Tenckhoff catheter is considered to be a permanent device, during CAPD the giving sets are changed every month, with some centres leaving them for 2 months. Originally there was poor acceptance of this new method because the dialysate was only available in glass bottles, which necessitated frequent opening of the dialysis circuit accompanied by a high incidence of peritonitis. By the time the dialysate became available in plastic bags, the technique had been simplified to comprise a closed-circuit system, with a resultant reduction in peritonitis. CAPD was introduced into the United Kingdom in 1978 and has since become an accepted form of dialysis treatment for patients with end-stage renal disease. More than 40 renal units now practice CAPD, accounting for $26 \%$ of the dialysis population and $14 \%$ of all patients on long-term renal replacement therapy. By 1985 it was estimated that about 27000 patients world wide, of whom 2450 were in the UK, were being treated by CAPD (Gokal, 1986). CAPD is more economical, allows greater patient mobility, does

Received 12 Oct. 1987; accepted 12 Feb. 1988. not require vascular access or any fluid and electrolyte restriction, and results in higher haemoglobin levels and better control of blood pressure. The technique is especially suited to the elderly and to diabetic patients, though extra insulin is required. Young patients awaiting transplantation should, however, be offered haemodialysis. Of the infective complications which occur in CAPD, peritonitis is the most important one, though deaths from peritonitis remain relatively rare (Spencer and Fenton, 1984; Working Party of BSAC, 1987; Peterson et al., 1987). Peritonitis remains the commonest cause of failure in CAPD treatment. Whilst this review will concentrate on peritonitis, the problems of exit site and tunnel infections will also be discussed.

\section{Peritonitis}

This does not have the classical clinical presentation of surgical peritonitis with rigid abdomen, toxic symptoms and septicaemia. Characteristically, CAPD peritonitis is a mild illness, the predominant feature of which is a "cloudy bag" caused by the presence of large numbers of white cells, usually in excess of 100 cells $/ \mathrm{mm}^{3}$. This may be accompanied by mild fever, abdominal pain and tenderness, with occasional difficulty in draining the exchange fluid. Positive blood cultures are extremely rare. The incubation period of peritonitis is uncertain, probably only 1-2 days. Symptoms usually disappear within $48 \mathrm{~h}$ following the instigation of appropriate antimicrobial treatment. It is probable that only small numbers of micro-organisms are necessary to produce peritonitis, but that not all episodes of microbial contamination lead to peritonitis. The principal portal of entry for organisms (figure) is thought to be the lumen of the catheter. The commercial production of peritoneal dialysate under stringent quality control criteria makes this fluid an unlikely source of bacteria. The commonest cause of infection is touch contamina- 


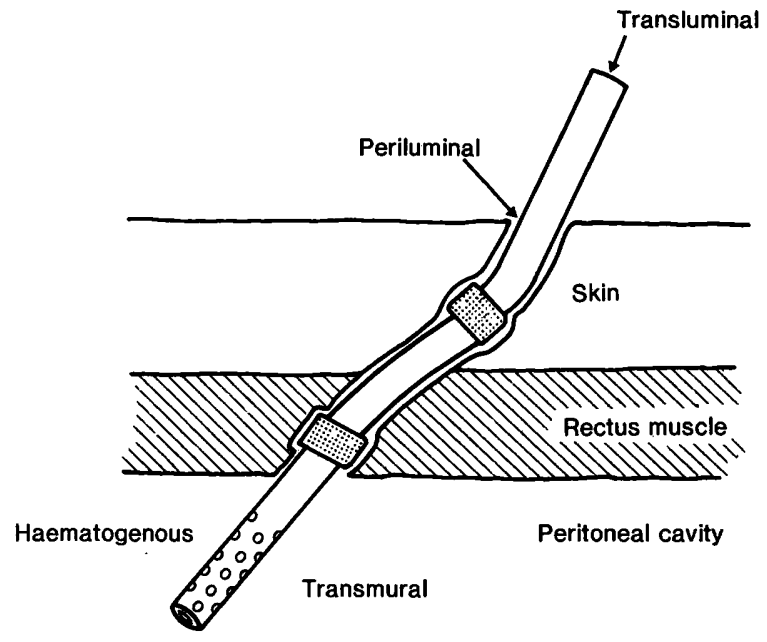

Figure. Portals of entry of micro-organisms.

tion during connecting or disconnecting a fresh dialysate bag. Horsman et al. (1986) found that isolates of coagulase-negative staphylococci (CNS) from the patient's skin were often identical to those strains causing subsequent peritonitis. Moreover, they found that most second infective episodes were caused by bacteria with plasmid profiles identical to those isolated in the initial infection. However, they were unable to determine whether recurrent infections were due to relapse after inadequate initial antibiotic treatment, or to reinfection with the same strain from the patient's own skin flora. A similar situation has been noted with infections caused by Staphylococcus aureus. However, in a subsequent paper, Eisenberg et al. (1987) found that in a series of 30 patients studied over 9 months most cases of peritonitis were not due to persistently colonising strains of CNS. The silastic Tenckhoff catheter never forms a completely sealed junction with the skin or subcutaneous tissues. The purpose of the single or double catheter cuffs is to prevent the penetration of bacteria around the catheter. Sometimes periluminal infection of the peritoneum does occur, usually in association with tunnel or exit-site infections (to be discussed later). Other portals of entry of micro-organisms into the peritoneal cavity are: intestinal-diverticular disease is a major cause and CAPD patients should never be allowed to become constipated; haematogenous-peritonitis due to Mycobacterium tuberculosis, Streptococcus pneumoniae and viridans streptococci have been reported; ascending - candida peritonitis due to vaginal candidosis; and environmental $-M$. chelone $i$ traced to tap water and pseudomonads from swimming baths.

\section{Host defences}

Phagocytic cells play very important roles in defence of the human host against microbial pathogens. In the peritoneal cavity, bacteria can be removed via the lymphatics to the reticuloendothelial system where they are phagocytosed and killed by macrophages. Peritoneal macrophages are also able to phagocytose and kill opsonised bacteria. The contribution of opsonic molecules is well recognised and a quantitative deficiency of opsonins can seriously compromise the bactericidal function of phagocytic cells. When these defence mechanisms are overcome, peritonitis develops with the characteristic exudation of polymorphs following the release of chemotaxins such as $\mathrm{C} 5 \mathrm{a}$ arising from bacterial activation of serum complement. The number of phagocytic cells in peritoneal fluid is usually low $\left(c .10^{4} \mathrm{cells} / \mathrm{ml}\right)$ and at these concentrations infecting bacteria are not sufficiently controlled. Verbrugh et al. (1984) found that $10^{6}$ cells/ $\mathrm{ml}$ were the minimum required to achieve bacteriostasis. The function of peritoneal macrophages can also be compromised by the commercial dialysis solutions themselves which have a low $\mathrm{pH}(5 \cdot 5)$ and a high osmolality. Both of these properties have been shown to have adverse effects on peritoneal macrophage function (Harvey et al., 1987). After instillation of large volumes of dialysate there is marked reduction in opsonic activity reflecting the low IgG and C3 concentrations (Verbrugh et al., 1983; Keane and Peterson, 1984). These low concentrations are roughly equivalent to those found in $0.5 \%$ normal human serum (Clarke and Easmon, 1986). Keane and Peterson (1984) identified a relationship between the level of opsonic activity and the incidence of peritonitis. They found that patients with "low" opsonic activity had an approximately 7 -fold greater incidence of peritonitis with $S$. epidermidis than those with a "high" opsonic activity. No heat stable opsonin specific for Escherichia coli is present in peritoneal effluent due to the low levels of C3. Even when opsonised, $E$. coli is phagocytosed less efficiently by macrophages than by polymorphonuclear leucocytes, which could explain the protracted course of peritonitis caused by enterobacteria. In Keane and Peterson's series, one-third of the patients with "high" opsonic activity were diabetics who have an increase in macromolecular permeability of the microvascular beds leading to higher IgG levels. It is worth noting that diabetics do not have an increased incidence of peritonitis. Peritoneal effluents capable of efficient opsonisation of staphylococci have been found, but only in those associated 
with dialysate dwell times of 6-10 h (Verbrugh et al., 1984). Current CAPD techniques require a more frequent exchange of peritoneal effluent, containing phagocytes, immunoglobulins and complement, for fresh commercial dialysate which is completely devoid of such antimicrobial activity and which adversely effects the phagocytic and bactericidal capacities of polymorphonuclear leucocytes and macrophages. It has been suggested that peritonitis could be managed more effectively by augmentation of local phagocytic defences (Keane and Peterson, 1984) by the addition of purified immunoglobulins to the dialysis fluid. By so doing the opsonic activity against $S$. epidermidis was increased. Clarke and Easmon (1986) demonstrated that an intravenous immunoglobulin preparation with no inherent opsonic activity displayed good opsonisation of $S$. epidermidis when combined with peritoneal effluent. Therefore immunoglobulin preparations could be considered as useful agents to boost peritoneal defences in those CAPD patients who suffer from repeated attacks of peritonitis.

\section{Causative organisms}

In CAPD patients the major causative organisms of peritonitis are coagulase-negative staphylococci (CNS) of which $S$. epidermidis is by far the commonest species found (Gruer et al., 1984). In a recent survey of 750 isolates from episodes of peritonitis in the Royal Hallamshire Hospital, Sheffield, the commonest organisms were CNS $(56 \%)$; the remainder of episodes were caused by $S$. aureus $(11 \%)$, enterobacteria $(11 \%)$, streptococci $(8 \%)$, Pseudomonas spp. (6\%), J-K diphtheroids $(3 \%)$, enterococci $(2 \%)$, Candida $(<1 \%)$, and miscellaneous $(2 \%)$. Of the 423 isolates of CNS, 317

Table I. Bacteria isolated from the peritoneal fluid of CAPD patients with peritonitis

\begin{tabular}{l|c}
\hline Organism & Number $(\%)$ \\
\hline Coagulase-negative staphylococci & $423(56)$ \\
Enterobacteriaceae & $79(11)$ \\
S. aureus & $78(11)$ \\
Streptococci & $57(8)$ \\
Pseudomonas spp. & $48(6)$ \\
J-K diptheroids & $24(3)$ \\
Enterococci & $17(2)$ \\
Candida spp. & $6(<1)$ \\
Miscellaneous* & $18(2)$ \\
Total & 750 \\
\hline
\end{tabular}

*Miscellaneous: Acinetobacter spp. 9, Achromobacter spp. 3, H. influenzae 2, Campylobacter spp. 2, anaerobes 4.
Table II. Identity of isolates of coagulase negative staphylococci, Enterobacteriaceae, streptococci and pseudomonads

\begin{tabular}{|c|c|c|c|}
\hline Group & Number & Species & Number \\
\hline \multirow{7}{*}{$\begin{array}{l}\text { Coagulase-negative } \\
\text { staphylococci }\end{array}$} & \multirow[t]{7}{*}{423} & S. epidermidis & 317 \\
\hline & & S. haemolyticus & 30 \\
\hline & & S. hominis & 26 \\
\hline & & S. warneri & 20 \\
\hline & & S. capitis & 7 \\
\hline & & S. saprophyticus & 5 \\
\hline & & Micrococcus & 18 \\
\hline \multirow[t]{6}{*}{ Enterobacteriaceae } & \multirow[t]{6}{*}{79} & E. coli & 25 \\
\hline & & Klebsiella spp. & 21 \\
\hline & & Enterobacter spp. & 18 \\
\hline & & Serratia spp. & 6 \\
\hline & & Proteus spp. & 6 \\
\hline & & Citrobacter spp. & 3 \\
\hline \multirow[t]{8}{*}{ Streptococci } & \multirow[t]{8}{*}{57} & Str. mitis & 22 \\
\hline & & Str. sanguis & 20 \\
\hline & & Str. salivarius & 5 \\
\hline & & Str. pneumoniae & 3 \\
\hline & & Str. agalactiae & 3 \\
\hline & & Str. bovis & 2 \\
\hline & & Str. milleri & 1 \\
\hline & & Str. mitior & 1 \\
\hline \multirow[t]{5}{*}{ Pseudomonads } & \multirow[t]{5}{*}{48} & P. aeruginosa & 27 \\
\hline & & P. maltophilia & 14 \\
\hline & & P. stutzeri & 4 \\
\hline & & P. cepacia & 2 \\
\hline & & P. putida & 1 \\
\hline
\end{tabular}

(75\%) were $S$. epidermidis. These findings are summarised in tables I and II.

$S$. epidermidis is regarded as an organism of low pathogenicity and yet is capable of causing peritonitis in patients on CAPD. Work has shown a defect in the effective opsonisation of $S$. epidermidis by peritoneal dialysis effluent (Verbrugh et al., 1983). This combined with the relative scarcity of phagocytes in the effluent $\left(c .10^{6} / \mathrm{L}\right)$, may explain the ability of $S$. epidermidis to initiate infection from small numbers washed into the peritoneal cavity during an exchange. Much work has concentrated on the ability of S. epidermidis to produce "slime" and its effect on host defence mechanisms. "Slimeproducing $S$. epidermidis" were described by Christensen et al. (1983) who found that $63 \%$ of clinically important strains grew as a "slimy film" on the walls of the culture tubes containing trypticase soya broth. Slime is not a true capsule, appears to be loosely bound to the cell surface and is easily removed by washing with water. Enhancement of slime production in vitro can be achieved by supplementing culture media with casamino acids and various sugars (Peters and Pulverer, 1984). Is slime involved with the adherence of staphylococci to the catheter? Ultrastructural studies by Peters $e t$ 
al. (1982) showed that slime only appeared $12 \mathrm{~h}$ after exposure of catheter segments to $S$. epidermidis. The kinetics and mechanics of adherence of $S$. epidermidis probably involves at least two processes. The first is an initial nonspecific binding related to surface charge or hydrophobic interactions, or both, between the cell surface and the surface of the plastic devices (Dunne and Franson, 1986). The ability of micro-organisms to produce slime at this stage is not significant (Pascual et al., 1986). The second is colonisation, as expressed as a function of slime production. The slime surrounds the microcolonies of staphylococci and cements them firmly to the catheter surface.

Slime production has been suggested as a marker for pathogenicity of $S$. epidermidis in catheterassociated infection (Davenport et al., 1986) and CAPD peritonitis (Kristinsson et al., 1986a). In these studies, recurrent peritonitis was more likely to occur with slime-producing strains. However, West et al. (1986) could not link the presence of slime-producing staphylococci with complications in CAPD peritonitis. Other studies have examined the effect of slime on the activity of human neutrophils. Johnson et al. (1986) found that separated slime interfered with several polymorphonuclear leucocyte functions such as chemotaxis, degranulation and phagocytosis. Kristinsson et al. (1987) found that the presence of slime on the staphylococcal cell does not appear to interfere with opsonophagocytosis.

Infection with S. aureus is particularly difficult to treat and eradicate without resorting to removal of the peritoneal catheter. It produces a more severe form of peritonitis and tends to cause abscesses. The isolation of anaerobes from CAPD peritonitis may indicate underlying bowel pathology. $P$. aeruginosa infection is difficult to cure and 10 cases of peritonitis failed to respond to appropriate antibiotic treatment given up to 4 weeks (Krothapalli et al., 1982). Removal of the Tenckhoff catheter in each patient was required because sinus tract infections developed. An equally gloomy picture pertains with fungal peritonitis, although this is a rare condition. In a review of the literature and their own experience with 11 cases, Eisenberg $e t$ al. (1986) found that prompt appropriate therapy was essential. The recommended therapy for most patients is removal of the catheter and systemic antifungal treatment with amphotericin B. Intraperitoneal therapy with amphotericin B has been found to predispose to peritoneal fibrosis. However, in patients who are haemodynamically and metabolically stable, and for whom CAPD is desirable, a trial of antifungal chemotherapy is recommended before any decision to remove the catheter is taken. In a case of peritonitis caused by $P$. maltophilia it was found that there was a significant difference in its susceptibility to aminoglycosides and polymyxin when incubated at $30^{\circ} \mathrm{C}$ (resistant) and $37^{\circ} \mathrm{C}$ (susceptible) (Wheat et al., 1985). In view of the low initial temperature of peritoneal dialysate, this may have implications in selecting a suitable agent for treating cases of peritonitis caused by $P$. maltophila. Other unusual causes of CAPD peritonitis have included Campylobacter spp. in two cases after gastroenteritis (Kristinsson et al., 1986b).

\section{Laboratory diagnosis of peritonitis}

Rapid and accurate diagnosis of the aetiology of peritonitis is essential if the patient is to be given the most appropriate chemotherapy. Conventional microbiological methods have often given negative results despite the presence of inflammatory cells and clinical evidence of infection. These cases of "sterile peritonitis" probably reflect the inadequacy of the microbiological techniques used. The false negative results could be due to embedded organisms (Peters et al., 1982) or to the poor survival of gram-positive organisms in peritoneal dialysate (Sheth et al., 1986). Therapy directed against grampositive cocci must always be considered in culturenegative peritonitis. Eosinophilic peritonitis (Gokal et al., 1981) runs a somewhat benign course for several weeks, occurring early in CAPD treatment and probably represents a reaction to some component of the CAPD system.

Drainage bags should be delivered intact, and without delay, to the laboratory, or stored at $4^{\circ} \mathrm{C}$ until this is possible. The fluid is removed aseptically. As the number of micro-organisms is low, as large a volume as possible should be sampled. Laboratories should aim for at least a $90 \%$ positive culture rate from infected i.e., cloudy, CAPD fluid (BSAC Working Party, 1987). Attempts to improve the rate of recovery of organisms have included: enrichment culture of the effluent with thioglycollate broth (Knight et al., 1982); use of pour plates (Fenton, 1982); closed filtration system with a $0.45 \mu \mathrm{m}$ filter through which $100 \mathrm{ml}$ of effluent are passed; radiometric detection (Males et al., 1986); and total volume culture (Dawson et al., 1985). Problems with contamination and blockage of filters occur with some of these procedures. The culture plates should be incubated aerobically in a $\mathrm{CO}_{2}$-enriched atmosphere and anaerobically, for $72 \mathrm{~h}$, and examined at daily intervals. A direct gram-stained smear of the dialysate has proved unsuitable for demonstrating bacteria. However, a 
positive result can be extremely useful and such an examination should always be performed, preferably by experienced operators. When organisms are detected microscopically they appear to be either adherent to or sequestered inside cells, usually polymorphonuclear leucocytes. Thus physical or chemical techniques capable of disrupting these cells could improve the rate of bacterial detection. This has proved to be the case with the use of lysiscentrifugation (Spencer and Ahmad, 1986) and ultra-sonics (Dabbs et al., 1987). Of 90 samples from patients with peritonitis, 25 were found to have antibacterial activity. Of the remaining 65 samples, the detection rates of potential pathogens were: pour plates $48(74 \%)$, centrifuge deposit 51 $(78 \%)$, and lysis centrifugation $56(86 \%)$. For the 25 samples in which antibacterial activity was detected, results were $7(28 \%), 6(24 \%)$ and $13(52 \%)$ respectively. Fifty specimens of peritoneal fluid were tested by sonication, of which $42(84 \%)$ yielded clinically significant isolates. Six of the eight negative cultures were from patients already on antimicrobial treatment. Pour-plate and centrifugedeposit cultures without sonication were positive in $39(78 \%)$ and $34(68 \%)$ of cases respectively. This latter technique is now the standard laboratory method at the Royal Hallamshire Hospital, Sheffield, for culturing CAPD effluent.

Residual antibiotic activity can be removed with absorbent resin, thereby increasing the yield of positive cultures.

\section{Treatment of peritonitis}

Once the diagnosis of peritonitis has been made, empirical antibiotic treatment must commence as soon as possible, before the laboratory results are available. Therefore, it is essential that knowledge of any prevalent organisms and their antimicrobial susceptibilities are known. The choice of agent(s), route of administration, dosing schedules and length of treatment have recently been extensively and effectively reviewed in the UK and the USA (Working Party BSAC 1987; Keane et al., 1987). A combination of an aminoglycoside and vancomycin appears to be the favoured empiric treatment. Once the organism is identified and its antibiotic susceptibility determined, one or other of these agents can be discontinued. Concern over the potential ototoxicity of an aminoglycoside + vancomycin combination has led some authors to propose alternative treatment regimens such as a combination of aztreonam plus teicoplanin, a glycopeptide antibiotic with little or no ototoxicity (Neville et al., 1987). Use of the Limulus lysate assay has been advocated as a rapid and sensitive measure of gram-negative peritonitis. An additional bonus would be that the majority of patients, who will have peritonitis caused by gram-positive bacteria (Clayman et al., 1987), are thereby excluded from exposure to aminoglycoside therapy. Recently the emergence of vancomycin resistance in strains of CNS in a patient with peritonitis was described (Schwalbe et al., 1987). All the isolates were $S$. haemolyticus which showed an increasing resistance to vancomycin during therapy. It is possible that $S$. haemolyticus is unique among CNS in being prone to develop resistance to vancomycin. Gruer et al. (1984) found that of 30 episodes of peritonitis caused by CNS, in only one was the organism ( $S$. haemolyticus) not eradicated.

The route of antimicrobial administration is normally intraperitoneal, with or without additional intravenous therapy. Normally the peritoneal cavity contains fibrinogen and fibrinolysin. In inflammation the fibrinolysin activity is impaired, with consequent increases in fibrinogen. Thereafter fibrin will not be broken down and formation of fibrin filaments and clots will occur. Intraperitoneal antibiotics are, therefore, always given together with heparin to inhibit the formation of these fibrin clots and reduce the incidence of post-infective adhesions of the peritoneal membrane. Peritoneal lavage has little to commend itself in the management of peritonitis. Treatment by oral antibiotics has been advocated (Neville et al., 1987) and the new quinolone compounds have been studied as possible therapeutic agents. Early pharmacokinetic studies have suggested that therapeutic concentrations of ciprofloxacin may be achievable against bacterial isolates commonly associated with CAPD peritonitis (Fleming et al., 1987). However amongst patients taking concurrent oral aluminium-containing antacids that also act as phosphate binders, a pronounced reduction in ciprofloxacin levels were found. Weissauer-Condon et al. (1987) concluded on the basis of in-vitro tests in peritoneal fluid that peritonitis due to staphylococci and pseudomonads cannot be treated effectively with the quinolones.

The choice of antibiotics is usually influenced by conventional susceptibility testing. However, it should be recognised that some antibiotics lose activity in peritoneal dialysis fluid (Sewell and Golper, 1982; Verbrugh et al., 1984; Craddock et al., 1987; Weissauer-Condon et al., 1987). This decrease may result from the low $\mathrm{pH}$, high osmolality or urea concentration in dialysis fluid. High concentrations of calcium and magnesium may also partly explain the reduced activity of the aminoglycosides. It is advocated that antibiotics 
chosen for the treatment of peritonitis should be investigated first in dialysis effluent.

Relapses have been reported in patients adequately treated with vancomycin or cephalothin plus tobramycin (Buggy et al., 1984). Sequestration of viable staphylococci within neutrophils in the peritoneal fluid was demonstrated. When rifampicin, an antibiotic known to readily penetrate and accumulate in leucocytes, was added to the treatment regimen resolution occurred and no relapses occurred. Similar results have followed the use of clindamycin, another antibiotic known to be taken up by leucocytes and macrophages (Cohen and Bailey, 1984).

Other causes of residual viability in the presence of antimicrobial agents have been proposed. Evans and Holmes (1987) suggested that $S$. epidermidis could retain viability, despite continuous exposure to vancomycin, due to the poor diffusion of the antibiotic through the dense aggregation of extracellular material (slime) in which the micro-colonies are embedded. Sheth et al. (1985) investigated the ability of slime-producing strains of CNS adherent to plastic catheters to survive exposure to bactericidal concentrations of nafcillin. They suggested that survival was due either to poor drug diffusion intracellularly, or avid binding of the drug by the slime matrix, or to an altered bacterial metabolic state which renders them less susceptible to the antibiotic.

The optimal length of treatment remains unresolved; gram-positive peritonitis usually resolves in 7-10 days, whereas gram-negative peritonitis can require 3 weeks or more of therapy. Measurement of serum C-reactive protein to monitor the effectiveness of antibiotic therapy has been proposed as a way of determining effective treatment schedules (MacD. Agar and Flett, 1984). There is no evidence that antibiotic prophylaxis prevents peritonitis.

\section{Other infections}

Peritonitis can be secondary to infection of the skin tunnel through the abdominal wall in which the Tenckhoff catheter lies. Pain and signs of inflammation along the site of the tunnel occur and these infections are extremely difficult to eradicate. Removal of the catheter may be necessary. Exitsite infections present with redness, skin induration and sometimes a purulent exudate. Aggressive antibiotic treatment is necessary for both these infections which are usually caused by $S$. aureus. If the cuff becomes a focus of infection, antibiotic treatment alone will not eradicate the infection. "Cuff-shaving" or removal of the external cuff have been advocated in the management of exit site infections.

\section{Prevention of infection}

Because most episodes of peritonitis are due to accidental contamination, prevention has been studied extensively. Rigid adherence to aseptic procedures is most important and can be most effective. Despite careful training and supervision in hospitals whilst learning the procedures, many patients are discharged home without the benefit of home assessment or domicillary nursing care. Regular home visits are essential to discourage the patients from taking various short-cuts which modify their techniques. Survival analysis shows that when other host, agent and environmental factors are controlled, age (younger patients), low patient motivation and minimal social support are significant risk factors for peritonitis. Microbial contamination can occur via lapses in "patient responsibility" such as the care of the connector or care of the exit site, and "centre responsibility" such as faulty insertion of Tenckhoff catheters into the peritoneal cavity (Spencer and Fenton, 1984).

It was hoped that the incidence of peritonitis would decrease with the introduction of more sophisticated and safer connection devices. The introduction of the titanium adaptor appears to have reduced peritonitis rates, though this has never been subjected to the scrutiny of properly controlled clinical trials. Additional measures have included an extra clamp on the catheter to prevent air entering the transfer set; a $0 \cdot 2-\mu \mathrm{m}$ membrane in-line filter; use of heat via microwaves and ultraviolet light. Connectors which make use of iodine antiseptics include the Oreopoulos-Zellermann connector, the beta-cap and the Bazzato double bag systems (Oreopoulos et al., 1983). Sodium hypochlorite is used in the Buorocristiani system and the " $Y$ " set in which the lumen is filled with sodium hypochlorite during the dwell period and this agent is also used to disinfect caps and ends of the tubing set during the exchange procedure (Fenton et al., 1985).

It has been suggested that prophylactic use of chlorhexidine in the dialysis solution would prevent peritonitis. Junor et al. (1985) found that 11 of a group of 54 patients who sprayed connectors at each exchange with chlorhexidine $0.5 \%$ in $70 \%$ alcohol developed sclerosing peritonitis-an extremely serious complication of peritoneal dialysis. None of 108 patients who used povidone-iodine suffered from this problem which is thought to occur as a result of the leeching of plasticisers from the tubing and catheter. 
Controlled clinical trials have not been performed on all the aforementioned new devices or techniques. In the few that have been done, some have failed to show any significant differences between the control and study groups. Uncontrolled studies have shown only small reductions in the overall rate of peritonitis. The improvements usually occur when the high-risk patients are studied separately. These patients, who are usually small in number, contribute most to the incidence of peritonitis. Perhaps we should attempt to define these patients in advance by measuring aspects of their host defences and concentrating our efforts in their augmentation.

To reduce still further the rates of peritonitis we will also have to concentrate on the other routes of infection such as the periluminal pathway. We still have to look for new approaches to produce an effective sealing of the skin-catheter interface. To minimise the risk of haematogenous seeding, serious thought must be given to the concept of antibiotic prophylaxis for all dental procedures in such patients to prevent infection with viridans streptococci. Apart from the use of povidone-iodine all the new systems, devices or techniques have the drawback of increasing the complexity of the system and of increasing costs.

\section{The future}

The genesis of catheter-related infections is principally related to catheter design and placement rather than the material of contruction. Silicone

\section{REFERENCES}

Ash S R 1984 Biocompatibility and hydraulic function of Tenckhoff and Lifecath catheters. Peritoneal Dialysis Bulletin 4 Suppl: S103-S106.

Buggy B P, Schaberg D R, Swartz R D 1984 Intraleukocytic sequestration as a cause of persistent Staphylococcus aureus peritonitis in continuous ambulatory peritoneal dialysis. American Journal of Medicine 76: 1035-1040.

Christensen G D, Parisi J T, Bisno A L, Simpson W A, Beachey E H 1983 Characterization of clinically significant strains of coagulase-negative staphylococci. Journal of Clinical Microbiology 18: 258-269.

Clarke L A, Easmon C S F 1986 Opsonic activity of intravenous immunoglobulin preparation against Staphylococcus epidermidis. Journal of Clinical Pathology 39: 856-860.

Clayman M D, Raymond A, Colen D, Moffit C, Wolf C, Neilson E G 1987 The Limulus amebocyte lysate assay. A rapid and sensitive method for diagnosing early gram-negative peritonitis in patients undergoing continuous ambulatory peritoneal dialysis. Archives of Internal Medicine 147: 337340.

Cohen L, Bailey D 1984 Efficacy of intraperitoneal clindamycin in refractory peritonitis - report of two cases. Peritoneal Dialysis Bulletin 4: 92-94. has a unique property of maintaining squamous epithelial surfaces, as demonstrated by the normal histological appearances of the peritoneum even after use of a peritoneal catheter for several years. New catheter designs are being proposed. The "Tenckhoff chronic straight" is the commonest catheter in use, easily inserted and easily removed. The column-disk (Lifecath) catheter is currently undergoing European trials. With this catheter it is reported that exit-site infections are rare; the lifespan is twice that of the Tenckhoff design, but peritonitis rates are similär (Ash, 1984). Other catheters under investigation include the Missouritype swan neck, said to reduce the accumulation of sweat and decrease the incidence of exit-site infections, and the Toronto Western Hospital II which forms a good seal with the peritoneal cuff, and has silicone base disks to prevent dislodgement, but again no decrease in peritonitis rates have been reported.

Other future developments will examine constituents of the dialysate fluid, incorporation of antibiotics or disinfectants into catheter material, enhancement of host defences, possibly by the addition of immunoglobulins, and altering the charge on the catheter surface to prevent microbial attachment. As microbial adhesion to inanimate surfaces is a complex and multifaceted process, the role of the biofilm and strategies to inhibit its formation are being investigated (Holmes and Evans, 1986). The most appropriate antimicrobial treatment, duration and route of administration are still areas for further investigation.

Craddock C F, Edwards R, Finch R G 1987 Pseudomonas peritonitis in continuous ambulatory peritoneal dialysis: laboratory predictors of treatment failure. Journal of Hospital Infection 10: 179-186.

Dabbs D J W, Davies S, Spencer R C 1987 Laboratory diagnosis of peritonitis in CAPD. Lancet 2: 334-335.

Davenport D S, Massanari R M, Pfaller M A, Bale M J, Streed S A, Heirholzer W J 1986. Usefulness of a test for slime production as a marker for clinically significant infections with coagulase-negative staphylococci. The Journal of Infectious Diseases 153: 332-339.

Dawson M S, Harford A M, Garner B K, Sica D A, Landwehr D M, Dalton H P 1985 Total volume culture technique for the isolation of micro-organisms from continuous ambulatory peritoneal dialysis patients with peritonitis. Journal of Clinical Microbiology 22: 391-394.

Dunne W M, Franson T R 1986 Coagulase negative staphylococci: the Rodney Dangerfield of pathogens. Clinical Microbiology Newsletter 8: 37-42.

Eisenberg E S, Leviton I, Soeiro R 1986 Fungal peritonitis in patients receiving peritoneal dialysis: experience with 11 patients and review of the literature. Reviews of Infectious Diseases 8: 309-321.

Eisenberg E S, Ambalu M, Szylagi G, Aning V, Soeiro R 1987 Colonization of skin and development of peritonitis due to 
coagulase-negative staphylococci in patients undergoing peritoneal dialysis. Journal of Infectious Diseases 156: 478482.

Evans R C, Holmes C J 1987 Effect of vancomycin hydrochloride on Staphylococcus epidermidis biofilm associated with silicone elastomer. Antimicrobial Agents and Chemotherapy 31: 889-894.

Fenton P 1982 Laboratory diagnosis of peritonitis in patients undergoing continuous ambulatory peritoneal dialysis. Journal of Clinical Pathology 35: 1181-1184.

Fenton S S A et al. 1985 The reduction in the peritonitis rate among high-risk CAPD patients with the use of the Oreopoulos-Zellerman connector. Transactions of the American Society of Artificial Internal Organs 31: 560-564.

Fleming L W, Moreland T A, Scott A C, Stewart W K, White L O 1987 Ciprofloxacin in plasma and peritoneal dialysate after oral therapy in patients on continuous ambulatory peritoneal dialysis. Journal of Antimicrobial Chemotherapy 19: 493-503.

Ganter G 1923 Uber die Beseitigung giftiger Stoffe aus dem Blute durch Dialyse. Munchener Medizinische Wochenschrift 70: $1478-1480$.

Gokal R 1986 World wide experience, cost effectiveness and future of CAPD-its role in renal replacement therapy. In: Gokal R (ed) Continuous ambulatory peritoneal dialysis. Churchill Livingstone, Edinburgh, pp 349-369.

Gokal R, Ramos J M, Ward M K, Kerr D N S 1981 Eosinophilic peritonitis in continuous ambulatory peritoneal dialysis (CAPD). Clinical Nephrology 15: 328-330.

Gruer L D, Bartlett R, Ayliffe G A J 1984 Species identification and antibiotic sensitivity of coagulase-negative staphylococci from CAPD peritonitis. Journal of Antimicrobial Chemotherapy 13: 577-583.

Harvey D M, Sheppard K J, Morgan A G, Fletcher J 1987 Effect of dialysate fluids on phagocytosis and killing by normal neutrophils. Journal of Clinical Microbiology 25: 1424-1427.

Holmes C J, Evans R 1986 Biofilm and foreign body infectionthe significance to CAPD-associated peritonitis. Peritoneal Dialysis Bulletin 6: 168-177.

Horsman G B, MacMillan L, Amatnieks Y, Rifkin O, Vas S I 1986 Plasmid profile and slime analysis of coagulasenegative staphylococci from CAPD patients with peritonitis. Peritoneal Dialysis Bulletin 6: 195-198.

Johnson G M, Lee D A, Regelmann W E, Gray E D, Peters G, Quie P G 1986 Interference with granulocyte function by Staphylococcus epidermidis slime. Infection and Immunity 54: 13-20.

Junor B J R, Briggs J D, Forwell M A, Dobbie J W, Henderson I 1985 Sclerosing peritonitis-the contribution of chlorhexidine in alcohol. Peritoneal Dialysis Bulletin 5: 101-104.

Keane W F, Peterson P K 1984 Host defence mechanisms of the peritoneal cavity and continuous ambulatory peritoneal dialysis. Peritoneal Dialysis Bulletin 4: 122-127.

Keane W F, Everett E D, Fine R N, Golper T A, Vas S I, Petersen P K 1987 CAPD related peritonitis management and antibiotic therapy recommendations. Peritoneal $\mathrm{Di}$ alysis Bulletin 7: 56-68.

Knight K R, Polak A, Crump J, Maskell R 1982 Laboratory diagnosis and oral treatment of CAPD peritonitis. Lancet 2: 1301-1304.

Kristinsson K G, Spencer R C, Brown C B 1986a Clinical importance of production of slime by coagulase-negative staphylococci in chronic ambulatory peritoneal dialysis. Journal of Clinical Pathology 39: 117-118.

Kristinsson K G, Spencer R C, Brown C B $1986 b$ Campylobacter peritonitis in continuous ambulatory peritoneal dialysis. Journal of Infection 13: 199-200.

Kristinsson K G, Hastings J G M, Oxley K M, Spencer R C 1987 Studies of the pathogenesis of coagulase-negative staphylococcal infections using chemiluminescence and bioluminescence. In: Scholmerich et al. (eds) Bioluminescence and chemiluminescence, new perspectives. John Wiley, Chichester, pp 177-180.

Krothapalli $\mathrm{R}$ et al. 1982 Pseudomonas peritonitis and continuous ambulatory peritoneal dialysis. Archives of Internal Medicine 142: $1862-1863$

MacD.Agar J, Flett P 1984 C-reactive protein-marker of CAPD peritonitis. Peritoneal Dialysis Bulletin 4: 181-182.

Males B M, Walshe J J, Garringer L, Koscinski D, Amsterdam D 1986 Addi-chek filtration, BACTEC, and 10-ml culture methods for recovery of micro-organisms from dialysis effluent during episodes of peritonitis. Journal of Clinical Microbiology 23: 350-353.

Neville L O, Baillod R, Hamilton-Miller J M T, Brumfitt W 1987 CAPD Peritonitis. Lancet 1: 1320.

Oreopoulos D G, Vas S I, Khanna R 1983 Prevention of peritonitis during continuous ambulatory peritoneal dialysis. Peritoneal Dialysis Bulletin 3 Suppl: S18-S20.

Pascual A, Fleer A, Westerdaal N A C, Verhoef J 1986 Modulation of adherence of coagulase-negative staphylococci to teflon catheters in vitro. European Journal of Clinical Microbiology 5: 518-522.

Peters G, Pulverer G 1984 Pathogenesis and management of Staphylococcus epidermidis "plastic" foreign body infections. Journal of Antimicrobial Chemotherapy 14 Suppl D: 67-71.

Peters G, Locci R, Pulverer G 1982 Adherence and growth of coagulase-negative staphylococci on surfaces of intravenous catheters. Journal of Infectious Diseases 146: 479-482.

Peterson P K, Matzke G, Keane W F 1987 Current concepts in the management of peritonitis in patients undergoing continuous ambulatory peritoneal dialysis. Reviews of Infectious Diseases 9: 604-612.

Popovich R P, Moncrief J W, Decherd J F, Bornar J B, Pyle W K 1976 The definition of a novel portable/wearable equilibrium peritoneal dialysis technique. Abstracts of American Society of Artificial Internal Organs 5: 64.

Schwalbe R S, Stapleton J T, Gilligan P H 1987 Emergence of vancomycin resistance in coagulase-negative staphylococci. New England Journal of Medicine 316: 927-931.

Sewell D L, Golper T A 1982 Stability of antimicrobial agents in peritoneal dialysate. Antimicrobial Agents and Chemotherapy 21 : 528-529.

Sheth N K, Franson T R, Sohnle P G 1985 Influence of bacterial adherence to intravascular catheters on in-vitro antibiotic susceptibility. Lancet 2: 1266-1268.

Sheth N K, Bartell C A, Roth D A 1986 In vitro study of bacterial growth in continuous ambulatory peritoneal dialysis fluids. Journal of Clinical Microbiology 23: 10961098.

Spencer R C, Fenton P A 1984 Infective complications of peritoneal dialysis. Journal of Hospital Infection 5: 233-240.

Spencer R C, Ahmad W K 1986 Laboratory diagnosis of peritonitis in continuous ambulatory peritoneal dialysis by lysis and centrifugation. Journal of Clinical Pathology 39: 925-926.

Starling E H, Tubby A H 1894 On absorption from and secretion into the serous cavities. Journal of Physiology 16: 140-155.

Tenckhoff H, Schechter H 1968 A bacteriologically safe peritoneal access device. Transactions of American Society of Artificial Internal Organs 14: 181-187.

Verbrugh H A, Keane W F, Hoidal J R, Freiberg M R, Elliott 
G R, Peterson P K 1983 Peritoneal macrophages and opsonins: antibacterial defence in patients undergoing chronic peritoneal dialysis. Journal of Infectious Diseases 147: 1018-1029.

Verbrugh H A, Keane W F, Conroy W E, Peterson P K 1984 Bacterial growth and killing in chronic ambulatory peritoneal dialysis liquid. Journal of Clinical Microbiology 20: 199 203.

Weissauer-Condon C, Engels I, Daschner F D 1987 In vitro activity of four new quinolones in Mueller-Hinton broth and peritoneal dialysis fluid. European Journal of Clinical Microbiology 6: 324-326.
West T E, Walshe J J, Krol C P, Amsterdam D 1986 Staphylococcal peritonitis in patients on continuous peritoneal dialysis. Journal of Clinical Microbiology 23: 809-812.

Wheat P F, Winstanley T G, Spencer R C 1985 Effect of temperature on antimicrobial susceptibilities of Pseudomonas maltophilia. Journal of Clinical Pathology 38: 10551058.

Working Party of the British Society for Antimicrobial Chemotherapy 1987 Diagnosis and management of peritonitis in continuous ambulatory peritoneal dialysis. Lancet 1 : 845849. 